\title{
Absorbed radiation doses due to chronic ingestion of cesium-137 or strontium-90 by mice
}

\author{
J.-M. BERTHO ${ }^{1}$, N. SYNHAEVE ${ }^{1}$, H. MILOUDI ${ }^{2}$, J. STEFANI ${ }^{1}$, A. DESBRÉE ${ }^{2}$, \\ E. BLANCHARDON ${ }^{2}$, I. DUBLINEAU ${ }^{1}$
}

(Manuscript received 14 June 2011, accepted 12 December 2011)

ABSTRACT The knowledge of the absorbed radiation dose is essential in order to interpret the results of animal experiments with chronic ingestion of radionuclides by rodents. In order to evaluate this absorbed dose, we applied the dose conversion factors proposed by ICRP publication 108 to mouse chronic ingestion experiments with $20 \mathrm{kBq} . \mathrm{L}^{-1}{ }^{137} \mathrm{Cs}-$ or ${ }^{90} \mathrm{Sr}$-contaminated water. The results indicated that wholebody absorbed doses were $9 \mathrm{mGy}$ and $10 \mathrm{mGy}$ by the end of 20 weeks of ${ }^{137} \mathrm{Cs}$ or ${ }^{90} \mathrm{Sr}$ ingestion, respectively. These results of dose calculations were compared with results obtained with a more refined method using published organ-specific absorbed fractions of energy. There was good agreement between the two methods, indicating that, despite the simple hypotheses used to apply the ICRP 108 dose conversion factors to our mouse model, this method allows one to calculate in a simple and reliable way the absorbed radiation dose received by the rodents during long-term experiments on chronic ingestion of radionuclides.

Keywords: Chronic contamination / absorbed dose / ICRP 108 / 137-cesium / 90-strontium

\section{Introduction}

Decades after major nuclear accidents, ${ }^{137} \mathrm{Cs}$ and ${ }^{90} \mathrm{Sr}$ are the two main long-term remnant radionuclides contributing to human exposure. These radionuclides can be found in all compartments of the environment, including food chains leading to humans. As a result, large populations are ingesting daily small amounts of these radionuclides (Cooper et al., 1992; De Ruig and Van der Struijs, 1994; Handl et al., 2003). However, the health consequences of such chronic ingestion of low quantities of radionuclides remain difficult to delineate, due to the complexity of exposure. We thus used a rodent model of chronic contamination with drinking water containing either ${ }^{137} \mathrm{Cs}$ or ${ }^{90} \mathrm{Sr}$ at a concentration of either $6.5 \mathrm{kBq} . \mathrm{l}^{-1}$ for rats

\footnotetext{
1 Institut de radioprotection et de sûreté nucléaire (IRSN), PRP-HOM, SRBE, LRTOX, Laboratoire de radiotoxicologie expérimentale, BP 17, 92262 Fontenay-aux-Roses, France.

2 Institut de radioprotection et de sûreté nucléaire (IRSN), PRP-HOM, SDI, LEDI, Laboratoire d'évaluation de la dose interne, BP 17, 92262 Fontenay-aux-Roses, France.
} 
(Tourlonias et al., 2010) or $20 \mathrm{kBq} . \mathrm{l}^{-1}$ for mice (Bertho et al., 2010; Synhaeve et al., 2011). In both models, this radionuclide concentration leads to a daily chronic intake in the range of 75-90 Bq per day and per animal, in a similar range to what was estimated for populations living in countries contaminated by the Chernobyl accident (Cooper et al., 1992; Handl et al., 2003). These studies showed that the contamination of rodents by ${ }^{137} \mathrm{Cs}$ induced some modifications in various physiological systems. For instance, chronic contamination with ${ }^{137} \mathrm{Cs}$ induced a modification of sleep-wake cycles in rats (Lestaevel et al., 2006), which may be associated with a neuroinflammatory reaction induced by the ingestion of radionuclides (Lestaevel et al., 2008). Other modifications of physiological systems are also induced by ${ }^{137} \mathrm{Cs}$ ingestion such as the cardiovascular system (Gueguen et al., 2008), the vitamin D metabolism (Tissandié et al., 2006) and the steroid hormone metabolism (Grignard et al., 2008). However, most of the observed modifications are at the molecular level (such as gene expression modifications or variation in protein synthesis) without any pathological consequence on the health status of animals (Lestaevel et al., 2010). By contrast, other physiological systems such as the haematopoietic system and the immune system are not modified by the chronic ingestion of ${ }^{137}$ Cs (Bertho et al., 2010; 2011).

The mechanisms by which the ingestion of these low concentrations of radionuclides induced these biological effects remain difficult to understand. In fact, biokinetic studies in these rodent models showed low concentrations of these two radionuclides, with heterogeneous organ distribution, both for ${ }^{137} \mathrm{Cs}$ (Bertho et al., 2010; Tourlonias et al., 2010), and for ${ }^{90} \mathrm{Sr}$ (Synhaeve et al., 2011). For instance, striated muscles, liver and kidney showed a higher ${ }^{137} \mathrm{Cs}$ concentration as compared with the mean ${ }^{137} \mathrm{Cs}$ concentration in the whole body (Bertho et al., 2010). Such variations in ${ }^{137} \mathrm{Cs}$ concentrations were also observed in humans (Métivier et al., 2000; Bandazhevsky, 2003; Leggett et al., 2003). Moreover, the mean concentration of ${ }^{137} \mathrm{Cs}$ tends to increase with the age of the animals up to 9 weeks old. By comparison, the ${ }^{90} \mathrm{Sr}$ repartition is strictly limited to the skeleton, with mainly an increase in ${ }^{90} \mathrm{Sr}$ concentration during bone growth. As a result, dose distribution in the animals depends on both the radionuclide distribution in the body, and also the age- and gender-dependent distribution of these radionuclides and the nature of emitted ionising radiation, and should be highly heterogeneous. However, in order to evaluate the absorbed radiation dose in these rodent models, we used the simplified animal model proposed by the ICRP publication 108 (2008).

A modelling of the environment was proposed by the ICRP publication 108 (2008) for radiation protection purposes. This modelling is based upon three reference plants and nine reference animals, representing most of the ecosystems (ICRP, 2008). A simplified geometry was defined for each of these plants and animals. For the rat model, the geometric representation is a solid ellipsoid of 
$20 \mathrm{~cm}$ length and 5- and 6-cm main and secondary diameters, and a mass of $315 \mathrm{~g}$. For each of these organisms, dose conversion factors (DCFs) from the wholeorganism activity concentration to the resulting dose rate were defined in $\left(\mu \mathrm{Gy} \mathrm{day}^{-1}\right) /\left(\mathrm{Bq} \cdot \mathrm{kg}^{-1}\right)$ for numerous radionuclides. Several hypotheses were made in addition to the simplified geometry of the animals (ICRP, 2008). Notably, the organism is considered as a medium of homogeneous density in which the radionuclide is homogeneously distributed. We used the rat model of ICRP publication 108 and DCF for either ${ }^{137} \mathrm{Cs}$ or ${ }^{90} \mathrm{Sr}$, combined with the timedependent activity concentrations, in order to calculate absorbed radiation doses from chronic ingestion exposure through ingestion of these radionuclides.

\section{Material and methods}

\subsection{Animals and radionuclide concentration}

$\mathrm{Balb} / \mathrm{C}$ mice were used throughout the study. Animals were contaminated through drinking water at a concentration of $20 \mathrm{kBq} \cdot \mathrm{L}^{-1}$ of either ${ }^{137} \mathrm{Cs}$ or ${ }^{90} \mathrm{Sr}$. Parent contamination started two weeks before mating and offspring were euthanised (5 to 6 animals per time point) at birth, and 3 (age of weaning), 6, 9, 12, 16 and 20 weeks of age, as previously described (Bertho et al., 2010). As a result, offspring were internally contaminated through placental transfer during foetal life, then through lactation during the post-natal period and through drinking water after weaning. All experiments were submitted to the animal care committee of the IRSN and conformed to French regulations for animal experiments (Ministry of Agriculture act \# 8 7-848, October 19th 1987, modified May 29th 2001). At each time point organs were collected and radionuclide content was measured according to previously described methods (Tourlonias et al., 2010; Synhaeve et al., 2011). Starting from these data, the mean body burden at each time point was calculated for each individual animal. For ${ }^{137} \mathrm{Cs}$ ingestion, the mean body burden varies from $7.6 \pm 0.8 \mathrm{kBq} \cdot \mathrm{kg}^{-1}$ at birth up to $12.7 \pm 1.8 \mathrm{kBq} \cdot \mathrm{kg}^{-1}$ at 20 weeks of age (Bertho et al., 2010). For ${ }^{90} \mathrm{Sr}$ ingestion, the mean body burden varies from $1.1 \pm 0.2 \mathrm{kBq} \cdot \mathrm{kg}^{-1}$ at birth up to $5.2 \pm 0.6 \mathrm{kBq} \cdot \mathrm{kg}^{-1}$ at 20 weeks of age (N. Synhaeve et al., 2011). For dose calculation purposes, the total body activity of each animal during each time interval was taken to be the mean of the total body activity measured in this animal at the next time point and the mean of total body activities measured in all animals euthanised at the last time point, starting from 0 at the time of mating.

\subsection{Body mass and mass class}

In each of the previously described experiments, animals were followed up individually for their body mass from weaning ( 3 weeks old) until the date of 
TABLE I

Dose conversion factors (DCFs) used in this study, expressed in $\left(\mu \mathrm{Gy} . \mathrm{day}^{-1}\right) /\left(\mathrm{Bq}^{\mathrm{kg}} \mathrm{kg}^{-1}\right)$, according to (ICRP, 2008).

\begin{tabular}{ccc}
\hline Radionuclide & Internal exposure & $\begin{array}{c}\text { External exposure in a uniformly } \\
\text { contaminated soil }\end{array}$ \\
\hline 137 -cesium & $4.1 \times 10^{-3}$ & $6.8 \times 10^{-3}$ \\
90 -strontium & $1.5 \times 10^{-2}$ & $3.0 \times 10^{-9}$ \\
\hline
\end{tabular}

sacrifice. As for total body activity, the body mass was estimated as the mean of the observed value at the next time point for each specific animal and the mean of masses of animals euthanised at the last time point, starting from 0 at the time of mating.

\subsection{DCF used for dose calculation}

The DCFs expressed in $\left(\mu \mathrm{Gy} \cdot \mathrm{day}^{-1}\right) /\left(\mathrm{Bq} \cdot \mathrm{kg}^{-1}\right)$ and used for dose calculation are indicated in table I. The DCF proposed by the ICRP takes into account the daughter products of radionuclides, provided the half-life of these daughter products is less than 10 days, i.e. only in the case where secular equilibrium could be reached during the exposure (ICRP, 2008). This is in fact the case for ${ }^{137} \mathrm{Cs}$, whose daughter product, ${ }^{137} \mathrm{ma}$, has a half-life of 153 seconds. Similarly, the daughter product of ${ }^{90} \mathrm{Sr}$, namely ${ }^{90} \mathrm{Y}$, has a half-life of 2.7 days.

For each time of sacrifice $i$, the radiation dose $D_{i}$ absorbed from the time $i$ - 1 to this time $i$ was calculated according to the following formula:

$$
D_{i}=D C F \times T_{i} \times A_{i} / M_{i}
$$

where $T_{i}$ is the time period since previous euthanasia ( $\left.i-1\right)$ expressed in days, and $A_{i}$ and $M_{i}$ the total body activity and body mass in the time interval $(i-1)$ to $i$ in $\mathrm{Bq}$ and $\mathrm{kg}$, respectively. The total dose absorbed up to a given time point $i$ is thus the sum of doses $D_{j}$ calculated for each time point $j \leq i$.

\subsection{Statistical analyses}

All calculations were done separately for individual animals. The results are presented as mean $\pm \mathrm{SD}$ of 5 to 6 animals for each data point. Data were statistically analysed independently for males and females using either two-way ANOVA or Student's t-test, as indicated in the text. Results were considered as significantly different at $\mathrm{p}<0.05$. 


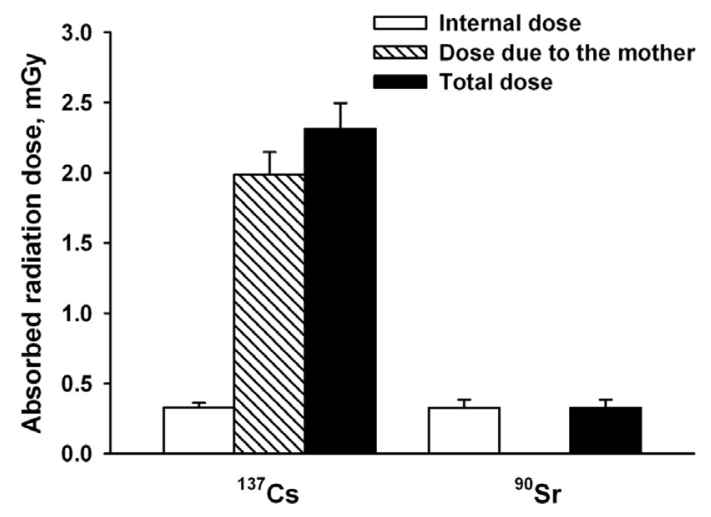

Figure 1 - Absorbed doses calculated for animals exposed to internal contamination with either ${ }^{137} \mathrm{Cs}$ (left panel) or ${ }^{90} \mathrm{Sr}$ (right panel) during foetal life (black bars) and distribution between the external dose due to the mother (hatched bars) and the dose due to internal irradiation (open bars).

\section{Results}

\subsection{Absorbed radiation doses during foetal life}

Animals are exposed during foetal life to both auto-irradiation due to internal contamination of the foetus and external irradiation due to the internal contamination of the mother. In order to take into account this external irradiation due to the mother, we used a DCF corresponding to an external irradiation due to contaminated soil surrounding the animal together with the mean body burden of the mother. Thus, as an approximation, the mother is assimilated to a medium of homogeneous density with a homogeneous contamination, as was previously proposed for modelling radiation doses to the embryo (ICRP, 2001). The mean body burden for the mother obtained in previous studies was $13.8 \pm 1.3 \mathrm{kBq} \cdot \mathrm{kg}^{-1}$ for ${ }^{137} \mathrm{Cs}$ ingestion (Bertho et al., 2010) and $10.4 \pm 2.4 \mathrm{kBq} \cdot \mathrm{kg}^{-1}$ for ${ }^{90} \mathrm{Sr}$ (Synhaeve et al., 2011). The results (Fig. 1) show that the total absorbed radiation dose at birth is $2.3 \pm 0.2 \mathrm{mGy}$ for animals ingesting ${ }^{137} \mathrm{Cs}$ and $0.33 \pm 0.06 \mathrm{mGy}$ for animals ingesting ${ }^{90} \mathrm{Sr}$. These results also show that the absorbed radiation dose due to internal contamination of the foetus is similar for both radionuclides. By contrast, the contribution to the total dose of external irradiation of the foetus due to the internal contamination of the mother is close to $85 \%$ in the case of ${ }^{137} \mathrm{Cs}$ and less than $1 \%$ in the case of ${ }^{90} \mathrm{Sr}$. This is due to the gamma rays emitted by ${ }^{137 \mathrm{~m}} \mathrm{Ba}$, which was taken into account due to its short half-life (153 seconds) for the establishment of the DCF for ${ }^{137} \mathrm{Cs}$. 


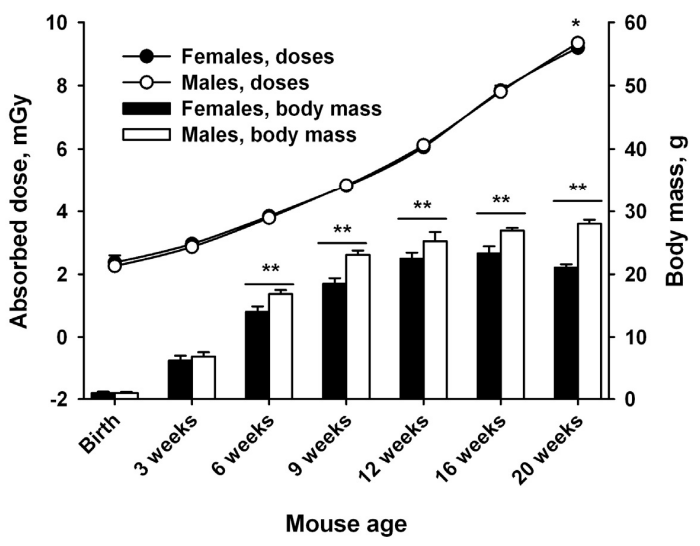

Figure 2 - Mean body mass (vertical bar) and whole-body absorbed doses calculated using the DCF (circles and lines) for contamination experiments through chronic ingestion of ${ }^{137} \mathrm{Cs}$. Differences between males (open bars and symbols) and females (closed bars and symbols) of the same age are significant for $*$ : $p<0.05$ and $* *: p<0.001(n=5)$.

\subsection{Absorbed radiation doses due to ${ }^{137}$ Cs ingestion}

Absorbed radiation doses were then calculated for each time point of the chronic ingestion experiment, taking into account the body mass class and total body activity class, as explained above. The results indicate that the evolution of body mass is less rapid in females as compared with males (Fig. 2), with significant differences appearing between the two populations at 6 weeks. However, the body mass remains stable from 12 weeks of age.

Absorbed radiation doses due to ${ }^{137} \mathrm{Cs}$ ingestion show a linear increase from birth to 20 weeks, peaking at $9.2 \pm 0.1 \mathrm{mGy}$ in females and $9.3 \pm 0.1 \mathrm{mGy}$ in males $(\mathrm{p}<0.05$ at 20 weeks).

\subsection{Absorbed radiation doses due to ${ }^{90}$ Sringestion and comparison with ${ }^{137} \mathrm{Cs}$}

The evolution of body mass of ${ }^{90} \mathrm{Sr}$-ingesting animals was similar to that observed in ${ }^{137}$ Cs-ingesting animals, with a slower body mass increase in females than in males (Fig. 3). Similarly, males were significantly heavier than females after 6 weeks and a stabilisation of body mass was observed from 12 weeks.

The evolution of the absorbed radiation dose is also close to linearity until 20 weeks, when the absorbed radiation dose is up to $9.7 \pm 0.1 \mathrm{mGy}$ in males and $10.6 \pm 0.1 \mathrm{mGy}$ in females $(\mathrm{p}<0.001$, see Fig. 3). However, the absorbed radiation dose increases more rapidly in females as compared with males, with significant 


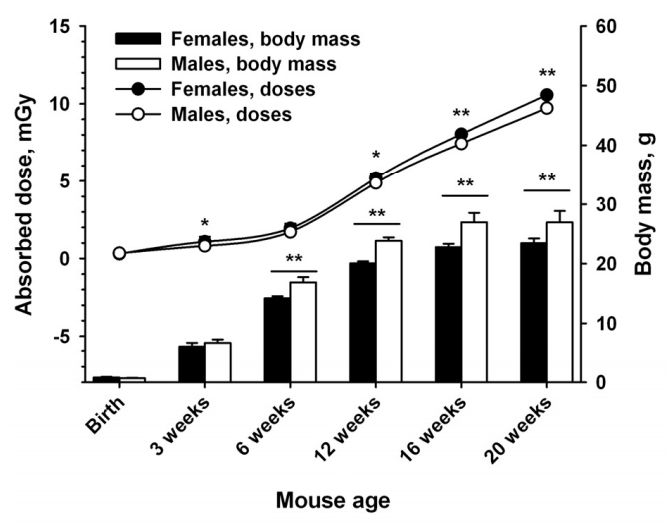

Figure 3 - Mean body mass (vertical bar) and whole-body absorbed radiation doses calculated using the DCF (circles and lines) for contamination experiments through chronic ingestion of ${ }^{90} \mathrm{Sr}$. Differences between males (white circles and bars) and females (black circles and bars) are significant for $*: p<0.05$ and $* *: p<0.001(n=5)$

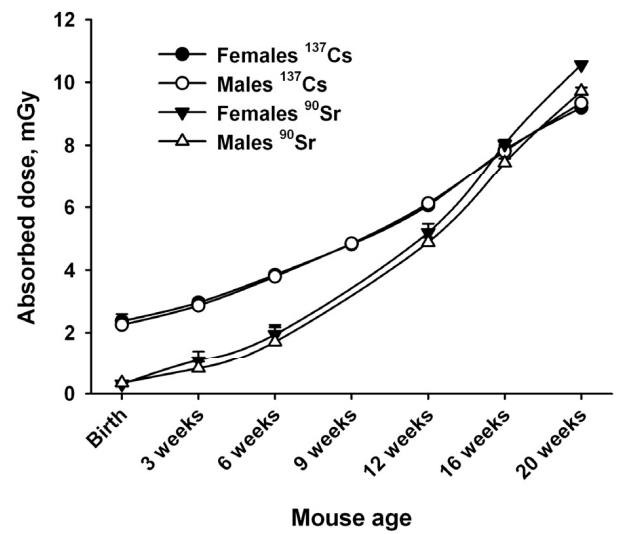

Figure 4 - Comparison of whole-body absorbed dose evolution in females (black symbols) and males (white symbols) ingesting either ${ }^{137} \mathrm{Cs}$ (circles) or ${ }^{90} \mathrm{Sr}$ (triangles).

differences appearing as soon as 3 weeks, and mainly after 12 weeks of age. This is linked to the mean ${ }^{90} \mathrm{Sr}$ body burden, which increases faster in females than in males due to the hormonal control of bone metabolism in adult females (data not shown).

The comparison between the two sets of experiments $\left({ }^{137} \mathrm{Cs} v s .{ }^{90} \mathrm{Sr}\right)$ shows that the absorbed dose increases faster in ${ }^{90} \mathrm{Sr}$-ingesting animals than in ${ }^{137} \mathrm{Cs}$-ingesting animals (Fig. 4), although it is lower at birth. This is linked to the higher energy 
deposition of beta rays from ${ }^{90} \mathrm{Sr}$ in body tissues as compared with the gamma rays from ${ }^{137} \mathrm{Cs}$, despite the lower body burden of ${ }^{90} \mathrm{Sr}\left(5.2 \pm 0.6 \mathrm{kBq} \cdot \mathrm{kg}^{-1}\right)$ as compared with ${ }^{137} \mathrm{Cs}\left(12.7 \pm 1.8 \mathrm{kBq} \cdot \mathrm{kg}^{-1}\right)$.

\subsection{Comparison with results obtained with another calculation method}

In order to confirm the results of dose calculations made with the DCF, we performed a more sophisticated dose calculation considering the cross-irradiation of organs. To that aim, specific absorbed fractions of energy (SAF) were calculated using a mouse voxel phantom (Stabin et al., 2006), composed of ten segmented organs. This method was applied to both ${ }^{137} \mathrm{Cs}$-ingesting and ${ }^{90} \mathrm{Sr}-$ ingesting animals.

For experiments with ${ }^{137} \mathrm{Cs}$, mean whole-body absorbed doses calculated using SAF were between $0.28 \pm 0.03 \mathrm{mGy}$ at birth and $7.9 \pm 0.9 \mathrm{mGy}$ at 20 weeks. For experiments with ${ }^{90} \mathrm{Sr}$, doses were in the range from $0.31 \pm 0.03 \mathrm{mGy}$ at birth up to $9.74 \pm 0.06 \mathrm{mGy}$ at 20 weeks. In order to make a direct comparison between the results of dose calculation by the two methods, the external radiation doses due to the mother during foetal life were omitted. The results of this comparison (Fig. 5) indicate that there is a significant difference, both for ${ }^{90} \mathrm{Sr}$ ingestion and for ${ }^{137} \mathrm{Cs}$ ingestion, and whatever the sex group considered. These differences were apparent between 6 weeks and 16 weeks for ${ }^{137} \mathrm{Cs}$ ingestion, and after 12 weeks for ${ }^{90} \mathrm{Sr}$ ingestion (Fig. 5). Interestingly, for ${ }^{137} \mathrm{Cs}$ ingestion, whole-body absorbed doses were overestimated with DCF calculations as compared with SAF calculations, while whole-body absorbed doses were underestimated with DCF calculations as compared with SAF calculations for ${ }^{90} \mathrm{Sr}$ ingestion. However, differences between the results of the two calculation methods were less than $8 \%$ at 20 weeks of age, indicating a good correlation between the results of the two calculation methods.

\section{Discussion}

The results presented here show that the application of the DCF to chronic contamination experiments through ingestion of radionuclides allowed us to calculate absorbed radiation doses of between $2.3 \pm 0.2 \mathrm{mGy}$ and $9.3 \pm 0.1 \mathrm{mGy}$ according to the age and sex for ${ }^{137} \mathrm{Cs}$-ingesting animals and between $0.33 \pm$ $0.06 \mathrm{mGy}$ and $10.6 \pm 0.1 \mathrm{mGy}$ for ${ }^{90} \mathrm{Sr}$ ingestion. This method of calculation using the DCF (ICRP, 2008) allows estimating in a simple and rapid way the mean body radiation doses absorbed by laboratory rodents in long-term contamination experiments, provided that biokinetic and organ mass data are available. These dose estimates have to be discussed in the context of previous results showing that chronic contamination through ${ }^{137} \mathrm{Cs}$ ingestion induced slight modifications of several physiological systems such as the cardiovascular system (Gueguen et al., 

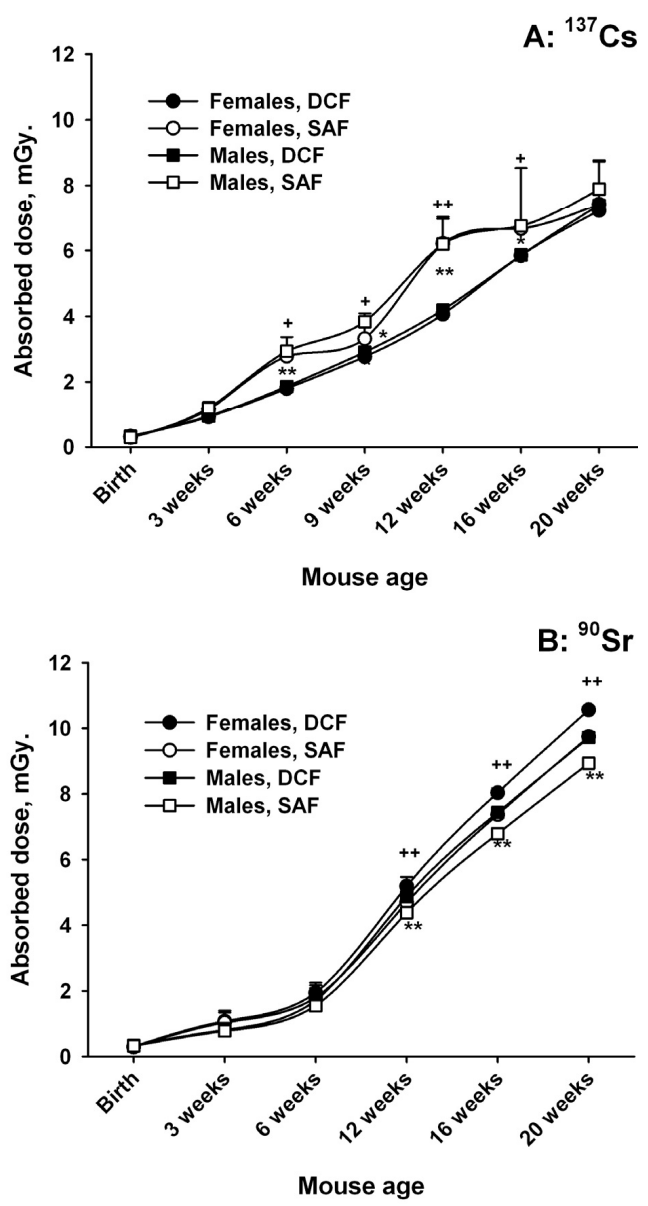

Figure 5 - Comparison of results according to two different methods for calculation of whole-body absorbed doses by animals contaminated through ingestion with ${ }^{137} \mathrm{Cs}(\mathrm{A})$ or with ${ }^{90} \mathrm{Sr}(\mathrm{B})$, using either the DCF (ICRP, 2008; black symbols) or specific absorbed fractions (SAF) of energy (Stabin et al., 2006; white symbols). Two-way ANOVA analysis showed significant difference between the two calculation methods both for males (circles, $F_{(1,50)}=31.3$, $p<0.001$ ) and for females (squares, $F_{(1,50)}=44.0, p<0.001$ ). Differences at each time point between the results of the two calculation methods for females are significant for $*: p<0.05$ and $* *: p<0.001$ and for males for $+:$ p $<0.05$ and ++ : $p<0.001$.

2008), vitamin D metabolism (Tissandié et al., 2006) and steroid hormone metabolism (Grignard et al., 2008). Most of these modifications are variations in specific gene expression or protein concentrations. The absorbed radiation dose presented here, below $10 \mathrm{mGy}$ for ${ }^{137} \mathrm{Cs}$ ingestion, may explain only in part the limited physiological modifications observed in these previous experiments. 
However, the mechanisms by which intake of such low quantities of radionuclides induces detectable physiological modifications remain elusive and need to be delineated.

The use of the DCF relies on some hypotheses (ICRP, 2008). The first one is the simplified geometry of animals and their environment. This is a major limitation, since energy deposition in living tissues depends on the source-target geometry. In fact, the model used for rat representation is approximately twelve-fold larger than an adult mouse. Nevertheless, the good correlation observed between the results of the two different methods of calculation (between 6\% and 8\% difference depending on the radionuclide and the sex of animals at 20 weeks of age) suggests that this simplification used in the ICRP model has little impact on whole-body dose calculation. The use of a soil uniformly contaminated surrounding the animal in its hole as a substitute to calculate the external radiation dose due to the mother during foetal life is another important limitation. In this case we were not able to evaluate the uncertainty induced by this approximation in the external radiation dose calculation. Other limitations are parameters linked to animal housing such as the litter contamination, the presence of the bottle of drinking water containing the radionuclide in the upper part of the cage and the cross-irradiation of animals by neighbours. Litter contamination may be taken into account by using the DCF proposed for a superficially contaminated ground (ICRP, 2008), but other parameters would need additional modelling. Although the external radiation dose due to these parameters may be negligible in the case of ${ }^{90} \mathrm{Sr}$ contamination experiments, they may induce significant external irradiation in the case of ${ }^{137} \mathrm{Cs}$ contamination experiments. This is supported by the calculation of the external radiation dose due to the mother's contamination during foetal life.

The DCF model considers that plants and animals are made of a medium of homogeneous density in which radionuclides are homogeneously distributed (ICRP, 2008). Obviously, results from biokinetic experiments demonstrate that radionuclides are heterogeneously distributed, both for ${ }^{90} \mathrm{Sr}$, which is strictly localised in bones (Dahl et al., 2001; Synhaeve et al., 2011), and for ${ }^{137} \mathrm{Cs}$, whose concentration varies from $2 \mathrm{kBq} \cdot \mathrm{kg}^{-1}$ in the skin up to $30 \mathrm{kBq} \cdot \mathrm{kg}^{-1}$ in striated muscles of the adult mouse (Bertho et al., 2010). Tissue density also varies, although in lesser proportions, from the less dense tissues such as the lungs up to the densest tissues such as bones and teeth. However, we were able to verify that the use of the rat model proposed by the ICRP (2008) as a surrogate for the mouse does not induce large uncertainties in the calculation of the mean whole-body absorbed radiation dose for both radionuclides used in these studies. In fact, by using a second method of dose calculation based upon SAF previously established in a mouse voxel phantom (Stabin et al., 2006) we observed a good correlation between the doses estimated by these two methods, although small yet significant 


\section{ABSORBED RADIATION DOSES DUE TO CHRONIC INGESTION}

differences were observed. These differences indicate that it should be of major interest to use voxelised mouse and rat phantoms, as has already been described by others (Keenan et al., 2010), in order to limit uncertainties due to hypotheses on radionuclide distribution and organ density. Moreover, such a model would be required in order to calculate the tissue absorbed doses to specific targets of interest, according to the observed biological effects.

\section{REFERENCES}

Bandazhevsky Y.I. (2003) Chronic ${ }^{137}$ Cs incorporation in children's organs. Swiss med wkly 133, 488490.

Bertho J.M., Faure M.C., Louiba S., Tourlonias E., Stefani J., Siffert B., Paquet F., Dublineau I. (2011) Influence on the mouse immune system of chronic ingestion of ${ }^{137}$ Cs. J. Radiol. Prot. 31, 25-39.

Bertho J.M., Louiba S., Faure M.C., Tourlonias E., Stefani J., Siffert B., Paquet F., Dublineau I. (2010) Biodistribution of ${ }^{137} \mathrm{Cs}$ in a mouse model of chronic contamination by ingestion and effects on the hematopoietic system. Radiat. Environ. Biophys. 49, 239-248.

Cooper E.L., Zeiller E., Ghods-Esphahani A., Makarewicz M., Schelenz R., Frindik O., Heilgeist M., Kalus W. (1992) Radioactivity in food and total diet samples collected in selected settlements in the USSR. J. Environ. Radioact. 17, 147-157.

Dahl S.G., Allain P., Marie P.J., Mauras Y., Boivin G., Ammann P., Tsouderos Y., Delmas P.D., Christiansen C. (2001) Incorporation and distribution of strontium in bone. Bone 28, 446-453.

De Ruig W.G., Van der Struijs T.D. (1992) Radioactive contamination of food sampled in the areas of the USSR affected by the Chernobyl disaster. Analyst. 117, 545-548.

Grignard E., Gueguen Y., Grison S., Lobaccaro J.M., Gourmelon P., Souidi M. (2008) In vivo effects of chronic contamination with ${ }^{137} \mathrm{Cs}$ on testicular and adrenal steroidogenesis. Arch. Toxicol. 82, 583-589.

Gueguen Y., Lestaevel P., Grandcolas L., Baudelin C., Grison S., Jourdain J.R., Gourmelon P., Souidi M. (2008) Chronic contamination of rats with ${ }^{137}$ Cs radionuclide: Impact on the cardiovascular system. Cardiovasc. Toxicol. 8, 33-40.

Handl J., Beltz D., Botsch W., Harb S., Jakob D., Michel R., Romantschuk L.D. (2003) Evaluation of radioactive exposure from ${ }^{137} \mathrm{Cs}$ in contaminated areas of northern Ukraine. Health Phys. 84, 502-517.

ICRP (2001) Publication 88, Doses to the embryo and fetus from intakes of radionuclides by the mother. Ann ICRP 31, 1-518. Pergamon press (Oxford).

ICRP (2008) Publication 108 Environmental protection: The concept and use of reference animals and plants. Ann ICRP 38, 1-242. Pergamon press (Oxford).

Keenan M.A., Stabin M.G., Segars W.P., Fernald M.J. (2010) Radar realistic animal model series for dose assessment. J. Nucl. Med. 51, 471-476.

Leggett, R.W., Williams, L.R., Melo, D.R., Lipsztein, J.L., 2003. A physiologically based biokinetic model for caesium in the human body. Sci. tot. environ. 317, 235-255.

Lestaevel P., Dhieux B., Tourlonias E., Houpert P., Paquet F., Voisin P., Aigueperse J., Gourmelon P. (2006) Evaluation of the effect of chronic exposure to ${ }^{137} \mathrm{Cs}$ on sleep-wake cycle in rats. Toxicol. 226, 118-125.

Lestaevel P., Grandcolas L., Paquet F., Voisin P., Aigueperse J., Gourmelon P. (2008) Neuroinflammatory response in rats chronically exposed to ${ }^{137}$ Cs. Neurotoxicol. 29, 343-348.

Lestaevel P., Racine R., Bensoussan H., Rouas C., Gueguen Y., Dublineau I., Bertho J.M., Gourmelon P., Jourdain J.R., Souidi M. (2010) Césium 137 : Propriétés et effets biologiques après contamination interne. Méd. Nucl. 34, 108-118. 
Métivier H., Lorthioir S. (2000) Propriétés physiques et chimiques du césium, dans Le césium, de l'environnement à l'homme (D. Robeau, F. Daburon et H. Métivier eds) pp. 3-11. EDP sciences, Les Ulis.

Stabin M.G., Peterson T.E., Holburn G.E., Emmons M.A. (2006) Voxel-based mouse and rat models for internal dose calculations. J. Nucl. Med. 47, 655-659.

Synhaeve N., Stefani J., Tourlonias E., Dublineau I., Bertho J.M. (2011) Biokinetics of ${ }^{90} \mathrm{Sr}$ after chronic ingestion in a juvenile and adult mouse model. Radiat. Environ. Biophys. 50, 501-511.

Tissandié E., Gueguen Y., Lobaccaro J.M., Aigueperse J., Gourmelon P., Paquet F., Souidi M. (2006) Chronic contamination with ${ }^{137} \mathrm{Cs}$ affects vitamin D3 metabolism in rats. Toxicol. 225, 75-80.

Tourlonias E., Bertho J.M., Gurriaran R., Voisin P., Paquet F. (2010) Distribution of ${ }^{137}$ Cs in rat tissues after various schedules of chronic ingestion. Health Phys. 99, 39-48. 